ANL/ED/CP - 88478

CONF-960690--2

\title{
A SYSTEM FOR FAST NEUTRON RADIOGRAPHY
}

by

Raymond T. Klann

Argonne National Laboratory-West

P.O. Box 2528

Idaho Falls, ID 83403-2528
PCEIVED

APR 171996

OSTI

Paper to be submitted for publication at the

Fifth International Conference on Applications of Nuclear Techniques

Crete, Greece

June 9-15, 1996

Work supported by the U.S. Department of Energy, Reactor Systems, Development and Technology, under Contract W-31-109-Eng-38. 


\section{DISCLAMMER}

Portions of this document may be illegible in electronic image products. Images are produced from the best available original document. 
A system for fast neutron radiography

\author{
Raymond T. Klann \\ Engineering Division \\ Argonne National Laboratory \\ Post Office Box 2528 \\ Idaho Falls, Idaho 83403-2528
}

\begin{abstract}
A system has been designed and a neutron generator installed to perform fast neutron radiography. With this system, objects as small as a coin or as large as a waste drum can be radiographed. The neutron source is an MF Physics A-711 neutron generator which produces $3 \times 10^{10}$ neutrons/second with an average energy of $14.5 \mathrm{MeV}$. The radiography system uses x-ray scintillation screens and film in commercially available light-tight cassettes. The cassettees have been modified to include a thin sheet of plastic to convert neutrons to protons through elastic scattering from hydrogen and other low $\mathrm{Z}$ materials in the plastic. For film densities from 1.8 to 3.0 , exposures range from $1.9 \times 10^{7} \mathrm{n} / \mathrm{cm}^{2}$ to $3.8 \times 10^{8} \mathrm{n} / \mathrm{cm}^{2}$ depending on the type of screen and film.
\end{abstract}

Keywords: fast neutron radiography, neutron generator, non-destructive analysis, radiography, geometric unsharpness, Argonne National Laboratory

\title{
1. INTRODUCTION
}

Historically, radiography was first invented in 1895 with the discovery of X-rays by Roentgen. Radiography utilizing neutrons was first developed in the 1930's and 1940's by Kallman and Kuhn using a small accelerator source. The methods and processes developed by these researchers outlined in a 1948 publication are still being used today to perform thermal neutron radiography. ${ }^{1}$ Although, thermal neutron radiography has been thoroughly developed and is commercially available, very little research with fast neutrons has been performed.

It was reported by Berger that fast neutron radiography with activation foils is possible. ${ }^{2}$ Since that time, researchers in the United States and Japan have investigated fast neutron radiography at neutron energies at or below $1 \mathrm{MeV}$, but there is only one reference to neutron radiography being performed at neutron energies near $14 \mathrm{MeV}$. Richardson used calcium tungstate scintillator screens to obtain some reasonable radiographs in the 1970 's. ${ }^{3}$ With the advent of stronger neutron sources and a wider array of scintillator and converter screens in recent years, fast neutron radiography has been examined at Argonne National Laboratory (ANL) and enhanced to the point of being useful for industrial radiographic applications.

\section{SYSTEM DESCRIPTION}

\subsection{General system}

The neutron source and radiography system are installed in a small shielded room located below grade. The walls of the room are 1.8 meters consisting of boron impregnated concrete ( $0.16 \mathrm{wt} \%$ boron). The ceiling is 0.6 meters of concrete impregnated with boron $(0.33 \mathrm{wt} \%)$ and then backfilled by 2.8 meters of gravel. The room has a shaft allowing samples to be lowered from the room above. Entrance to the room is resricted and requires manually opening a large shield door which glides on air bearings.

The radiography system which includes a neutron generator, two support tables, a film cart, film cassettees, and lead shielding, is inherently simple but offers the widest range of flexibility in specifying process variables. The attached photograph shows the basic components of the system, however, the components necessary to support the operation of the neutron generator are not shown in the photograph. 
The source-to-detector distance can be varied from 0.01 to 2.5 meters by moving the film cart along a track mounted on the sample table. A ruler is affixed to the table adjacent to the track for direct indication of the source to image distance. The film cart uses two adapters- one to hold $18 \times 43 \mathrm{~cm}$ cassettees and one to hold $35 \times 43 \mathrm{~cm}$ cassettees. The adapters hold the cassettes in either a vertical or horizontal position with the center of the cassettee in line with the neutron generator. The sample table can handle reasonably large objects and loads up to $250 \mathrm{~kg}$.

Operation of the system is very simple. To radiograph an object: 1 . the neutron generator operating parameters are set, 2 . the film cassette is loaded in a darkroom, 3. the object is placed on the sample table, 4. the film cassette is placed on the film cart, 5. the film cart is positioned behind the sample, 6. the room is secured, 7. the neutron generator is operated for a specified time, and 8. the cassette is removed and taken to the darkroom for processing.

\subsection{Neutron source}

The neutron generator is a Model A-711 continuous yield neutron generator manufactured by the MF Physics Corporation. The neutron generator utilizes the $\mathrm{H}^{3}(\mathrm{~d}, \mathrm{n}) \mathrm{He}^{4}$ reaction in a minature sealed tube accelerator to produce a high output of fast neutrons from a collision of a mixed beam of deuterium and tritium ions with a deuterium-tritium loaded target. The neutron generator head (shown in the photograph) contains a Penning ion source, gas occlusion filaments, a scandium tritide/deuteride target and focusing and accelerating electrodes. Also shown in the photograph is a pressurized enclosure which contains the high voltage power supplies and a full-wave voltage doubler. The balance of the system is located outside the room and includes a control console and a closed loop cooling source that uses clean tap water to cool the target and freon-113 to cool the ion source.

The average neutron energy was determined by measuring the ratios of saturation activities and comparing them to the ratios of the cross-sections for the following reactions:

$$
\frac{N i^{58}(n, p) C o^{58}}{N i^{58}(n, 2 n) N i^{57}} \quad \frac{A l^{27}(n, \alpha) N a^{24}}{N i^{58}(n, 2 n) N i^{57}}
$$

Based on these measurements, the average neutron energy was found to be $14.55 \pm 0.09 \mathrm{MeV}$. Using the same reactions, the source was found to produce $2.98 \times 10^{10} \pm 8.1 \%$ neutrons/second at an operating voltage of $150 \mathrm{kV}$ and beam current of 2.5 $\mathrm{mA} .^{s}$

\subsection{Radiography cassettees and recording media}

Three different types of film cassettees are used - DuPont Cronex ${ }^{\otimes}$, Kodak X-Omatic ${ }^{\otimes}$, and spring-loaded aluminum cassettes that are used at ANL for thermal neutron radiography. The cassettees are loaded with two scintillating screens -one in front and one behind the film. Numerous scintillating screens were tested before Kodak Lanex ${ }^{\otimes}$ Fine screens were selected. ${ }^{6}$ These screens were found to offer the best resolution although several artifacts from the screen are apparent on the radiographs in the form of small slightly darker patches or spots. A thin $(1.5 \mathrm{~mm})$ piece of plastic is placed between the front of the cassettee and the front screen. The plastic serves as a proton source by elastic scattering from hydrogen and other low $\mathrm{Z}$ materials in the plastic. This plastic sheet is essential, as without it, the exposure times are excessive. ${ }^{6}$

\section{RADIOGRAPHIC PARAMETERS}

\subsection{Geometric Unsharpness and Enlargement}

When a radiograph is produced, a certain amount of distortion occurs. The distortion is a combination of geometric enlargement due to the object generally being larger than the source aperature and geometric unsharpness due to the distortion penumbra caused by a finite aperature size. The length to diameter (L/D) ratio is widely used as a simple means of characterizing the collimation of a system. The L/D ratio directly determines the resolution of the system. 
The resolution, or geometric unsharpness, is defined as

$$
U_{g}=\left(\frac{D}{L_{s}}\right) \cdot L_{f}
$$

where $\mathrm{L}_{\mathrm{f}}$ is the image to object distance, $\mathrm{D}$ is the source aperature size, and $\mathrm{L}_{\mathrm{s}}$ is the source to object distance. ${ }^{4}$ However, in an uncollimated system, the $\mathrm{L} / \mathrm{D}$ ratio is no longer meaningful and the geometric unsharpness has to be determined from measurements. For a point source, the geometric enlargement is defined by

$$
E_{g}=\frac{w}{2 L} L_{f}
$$

where $w$ is the width of the object. By measuring the size of an image on a radiograph compared to the actual size of the object, the geometric unsharpness can be determined by

$$
U_{g}=\frac{M_{R}-w}{2}-E_{g}
$$

where $M_{R}$ is the width of the image on the radiograph as measured to the edge of the distortion penumbra. Measurements for the fast neutron radiography system determined the geometric unsharpness to be approximately $2.25 \mathrm{~mm}$ as shown in the table. The geometric unsharpness is considerably worse than values for thermal neutron radiography with $L / D$ ratios greater than 10 , but it must be remembered that this is an uncollimated system so the $L / D$ ratio is essentially 1 .

\begin{tabular}{|c|c|c|c|c|c|c|}
\hline \multicolumn{7}{|c|}{$\begin{array}{c}\text { Geometric Unsharpness and Enlargement at } \mathrm{L}=150 \mathrm{~cm} \\
\text { (all measurements in millimeters) }\end{array}$} \\
\hline \hline Block & $\mathrm{w}$ & $\mathrm{L}_{\mathrm{s}}$ & $\mathrm{L}_{\mathrm{f}}$ & $\mathrm{E}_{\mathrm{g}}$ & $\mathrm{M}_{\mathrm{R}}$ & $\mathrm{U}_{\mathrm{g}}$ \\
\hline $5 \mathrm{~cm}$ & 50.8 & 1449.2 & 50.8 & 0.89 & 57 & 2.2 \\
\hline $10 \mathrm{~cm}$ & 50.8 & 1402 & 98 & 1.78 & 59 & 2.3 \\
\hline
\end{tabular}

\subsection{Exposure Rate}

The plane of radiography can be varied as mentioned previously, however, $1.5 \mathrm{~m}$ was found to be the optimum source-to-film distance when considering exposure time vs. image clarity. An exposure of $3.7 \times 10^{8} \mathrm{n} / \mathrm{cm}^{2}$ is needed to produce a radiograph with a density of 1.8 using the Kodak Lanex ${ }^{\otimes}$ Fine screens with Kodak TMG general radiography film. ${ }^{6}$ At $1.5 \mathrm{~m}$, the neutron flux is $4.2 \times 10^{5} \mathrm{n} / \mathrm{cm}^{2}-\mathrm{sec}$ which results in an exposure time of 15 minutes. It should be noted, that the DuPont Cronex ${ }^{\otimes}$, Quanta $^{\$}$, and $U V^{8}$ screens require considerably less exposure $1.9 \times 10^{7} \mathrm{n} / \mathrm{cm}^{2}$ to $1.3 \times 10^{8} \mathrm{n} / \mathrm{cm}^{2}$ for film densities between 2.2 and 3.0 (exposure time of 3 minutes) at the price of image resolution. ${ }^{6}$

\section{BENEFITS AND LIMITATIONS OF FAST NEUTRON RADIOGRAPHY}

Fast neutron radiography can offer a glimpse at the internals of objects where other traditional non-destructive analysis techniques fail. Thick objects, such as waste containers or large steel drums, can be probed with this system and it has been used to probe materials that are traditionally used as absorbers or shields for thermal neutrons and gamma rays like borated polyethylene, cadmium, hafnium, steel, lead, polyethylene, water, and concrete. Additionally, since cross-sections vary differently with energy, fast neutron radiography can be used as a complement to other forms of radiography. 
One immediate benefit over other forms of radiography is apparent in the attached radiograph. The radiograph shows a steel tape dispenser and a mug filled with water with spoons in it. Looking at the tape dispenser, it is evident that both the steel and plastic objects are clearly shown. Other forms of radiography only show detail in one material or the other. In this radiograph, considerable detail shows in the center of the tape through the dispenser and above it. Another benefit over thermal neutron radiography does not show in this radiograph but is obvious when considering that a sheet of cadmium was placed in front of the objects. The image of the mug clearly shows the water level in the mug, the hollow bottom of the mug, and the outline of the metal spoon in the water. The same result occurred when radiographing a steel can filled with water in which steel, aluminum, and poly objects were placed in the can. ${ }^{7}$ Based on these results, fast neutron radiography offers significant advantages over other forms of radiography- such as thermal neutron, epithermal neutron, $x$ radiography, and gamma radiography. No other form of radiography can show high $Z$ materials immersed in low $Z$ materials that are contained in a high $Z$ material. In addition, fast neutrons offers the benefit of being able to penetrate cadmium which thermal neutrons and $x$ rays cannot penetrate.

\section{ACKNOWLEDGEMENTS}

This work was supported by the United States Department of Energy, Nuclear Energy Programs, under contract W-31-109-Eng-38.

\section{REFERENCES}

1. H. Kallman, Research 1 (1947-48), p. 254.

2. H. Berger, "Some experiments in fast neutron radiography," Materials Evaluation 27, p. 245-253, December, 1969.

3. A.E. Richardson, "Improved images in $14.5 \mathrm{MeV}$ neutron radiography," Materials Evaluation 35, p. 52-58, April, 1977. 4. P. von der Hardt and H. Rottger, ed., Neutron Radiography Handbook, p. 16-18, D. Reidel Publishing Company, Dordrecht, Holland, 1981.

5. R.T. Klann and M.D. Natale, "Determining the flux and average neutron energy from a neutron generator," Transactions of the American Nuclear Society, I.O. Macke, ed., vol. 74, American Nuclear Society, Incorporated, 1996.

6. R.T. Klann and M.D. Natale, "Fast Neutron Radiography Research at ANL-W," Neutron Radiography (5) - Proceedings of the Fifth World Conference, proceedings not yet published.

7. R.T. Klann, "Fast Neutron (14.5 MeV) Radiography: A Comparative Study," Neutron Radiography (5) - Proceedings of the Fifth World Conference, proceedings not yet published.

\section{DISCLAIMER}

This report was prepared as an account of work sponsored by an agency of the United States Government. Neither the United States Government nor any agency thereof, nor any of their employees, makes any warranty, express or implied, or assumes any legal liability or responsibility for the accuracy, completeness, or usefulness of any information, apparatus, product, or process disclosed, or represents that its use would not infringe privately owned rights. Reference herein to any specific commercial product, process, or service by trade name, trademark, manufacturer, or otherwise does not necessarily constitute or imply its endorsement, recommendation, or favoring by the United States Government or any agency thereof. The views and opinions of authors expressed herein do not necessarily state or reflect those of the United States Government or any agency thereof. 


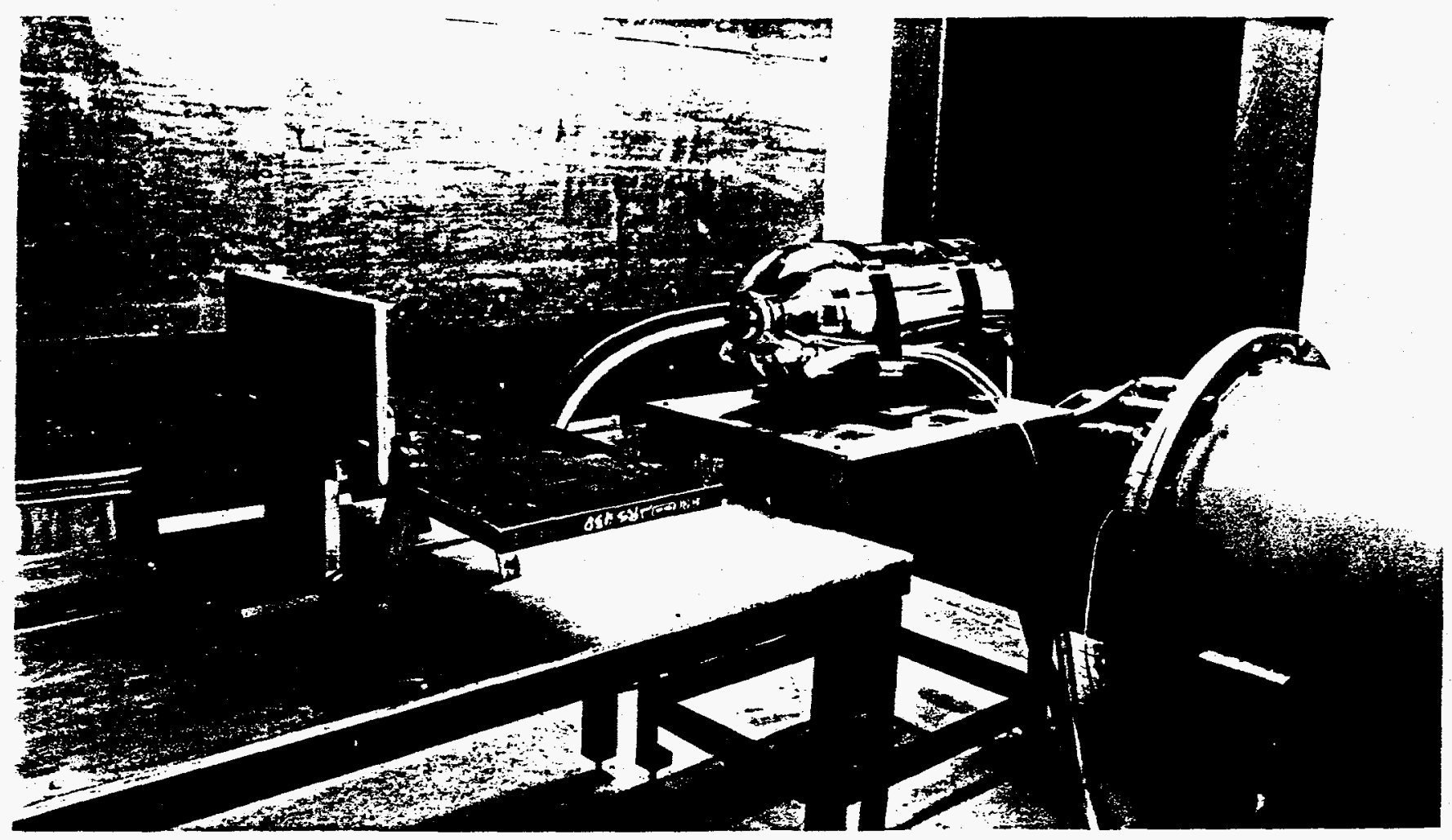

Photograph: Fast neutron radiography system located in the north radiography station cell at Argonne National Laboratory

$$
\text { Being Processed }
$$

Radiograph: Image of a tape dispenser and coffee mug taken with the FNR system at a distance of $150 \mathrm{~cm}$. Exposure time was 15 minutes using Kodak Lanex ${ }^{\circledR}$ Fine screens with Kodak TMG film. Film processing time was 2 minutes. 